УДК 339.138

$10.17213 / 2075-2067-2020-5-194-202$

\title{
УПРАВЛЕНИЕ ТЕРРИТОРИЯМИ МУНИЦИПАЛЬНЫХ ОБРАЗОВАНИЙ ПРИ ВЕДЕНИИ ГРАДОСТРОИТЕЛЬНОЙ ДЕЯТЕЛЬНОСТИ
}

\section{(C) 2020 г. Н. Г. Овчинникова, Е. И. Жидкова, В. А. Тимофеева}

\section{Донской государственный технический университет, г. Ростов-на-Дону, Россия}

Целью исследования является рассмотрение процесса управления территориями мунищипальных образований посредством ведения градострочтельной деятельности, иелью которого является создание наиболее благоприятных и комфортных условий для жизни населения и функиионирования города как изелостной системы.

Методологическую базу исследования представляет анализ нормативно-правового регулирования системы территориального планирования и застройки территорий муниципальных образований, экономических и эстетических принциипов возведения объектов строительства, применение которых способствует улучшению качества жизни населения на территории, повышению экономического роста региона.

Результаты исследования. Важным результатом данного исследования является выявление методологических предпосылок осуществления градостроительной деятельности на муниципальном уровне. Все внимание концентрируется на вопросах проектирования и застройки территориймуниципальных образований, нормативно-правового регулирования системы территориального планирования в Российской Федеращии, существующих принципах возведения городских объектов. Тем самым хочется отметить, что принятие градостроительных решений должно осуществляться на основе учета самых разнообразных факторов: экономических, правовых, эстетических, сочиальных, экологических и пр. Эффективными будут считаться те решения, которые принимают во внимание все эти критерии в комплексе и способствуют повышению качества жизни людей на данной территории.

Перспективу исследования составляет анализ, направленный на раскрытие механизмов осуществления градостроительной деятельности в условиях интенсивного освоения территорий муниципальных образований.

Ключевые слова: градостроительное проектирование; раџиональное использование; пространственная конфигурачия; территориальное планирование, градостроительное зонирование; документы территориального планирования.

\section{MANAGEMENT OF MUNICIPAL TERRITORIES IN URBAN PLANNING ACTIVITIES}

\section{(C) 2020 N. G. Ovchinnikova, E. I. Zhidkova, V. A. Timofeeva}

\section{Don State Technical University, Rostov-on-Don, Russia}

The purpose of the study is to consider the process of managing the territories of municipalities through the conduct of urban planning activities, the purpose of which is to create the most favorable and comfortable conditions for the life of the population and the functioning of the city as an integral system as a whole. 
The methodological base of the study is the analysis of the legal regulation of the system of territorial planning and development of the territories of municipalities, the architectural and aesthetic principles of the construction of construction projects, the use of which helps to improve the quality of life of the population on the territory, to increase the economic growth of the region.

The results of the study. An important result of this study is the identification of methodological prerequisites for the implementation of urban planning activities at the municipal level. All attention is focused on issues of design and development of municipal territories, legal regulation of the territorial planning system in the Russian Federation, existing principles for the construction of urban facilities. Thus, I would like to say that the adoption of urban planning decisions should be based on taking into account a wide variety of factors: architectural, legal, aesthetic, social, environmental, etc. Those decisions that take into account all these criteria in a complex and contribute to an increase in the quality of life will be considered effective people in the area.

The prospect of the study is an analysis aimed at revealing the mechanisms for the implementation of urban planning activities in the conditions of intensive development of the territories of municipalities.

Key words: urban planning; rational use; spatial configuration; territorial planning, urban zoning; territorial planning documents.

Введение. В настоящее время людей окружают большие города и густонаселённые пригороды, в связи с этим необходимо предусматривать ответственный подход к планированию застройки территорий [1, 2]. И поскольку в крупных городах уже мало свободной земли, то нужно профессионально подходить и к дальнейшему ее распределению. Чтобы эффективно застроить район, правильно рассчитать плюсы и минусы, и существует градостроительное проектирование [3], ведь именно от него зависит, насколько правильно будут построены жилые дома, здания, места отдыха, дороги и другие объекты, а соответственно, и безопасность горожан.

Градостроительное проектирование микрорайона должно отвечать определенным требованиям, возникшим в настоящее время. Концепция планировки микрорайона должна быть направлена на рациональное использование земельных ресурсов, не оказывать негативного воздействия на окружающую среду и не препятствовать эффективной жизнедеятельности населения $[4,5]$.

Актуальность работы заключается в том, что с каждым годом города развиваются все стремительнее. Развитие города как благоприятной среды жизнедеятельности человека предполагает наличие определенных градостроительных норм и правил, прописан- ных в градостроительной документации [6]. В связи с этим важным условием при планировке населенного места является изучение законодательства в области градостроительства и планировки населенных мест. Помимо этого, для улучшения качества жизни населения при планировке необходимо учитывать природные и климатические факторы местности $[7,8]$.

Таким образом, под градостроительным проектированием понимается многосторонний комплексный процесс, в ходе которого формируются пространственная конфигурация, планировка и застройка территории. Во время этого процесса оптимизируется размещение объектов жилищного строительства, городского хозяйства и социальной сферы, транспортных и инженерных коммуникаций, формируется архитектурный облик, обеспечивается функциональная связь всех необходимых для эффективного функционирования города элементов, при этом в приоритет ставятся мероприятия, связанные с улучшением состояния городской среды. Перечисленные выше действия необходимо осуществлять с учетом интересов граждан, общественных и государственных интересов, a также национальных, историко-культурных, экологических, природных и иных особенностей определенных территорий $[9,10]$. 
Другими словами, градостроительное проектирование - это комплексная работа, которая должна обеспечить население и субъектов предпринимательской деятельности объектами, правилами пользования землей и нормативами застройки. Ввиду разных экономических показателей, особенностей территории и климатической зоны, количества жителей и иных показателей для каждого населенного пункта, района и субъекта Российской Федерации эти нормативы будут отличаться. В результате этого градостроительное проектирование требует четкого понимания политических, социальных и экономических факторов [11].

Нормативно-правовая база обеспечения градостроительной деятельности. Основным нормативным документом для градостроительного проектирования является Градостроительный кодекс Российской Федерации от 29.12.2004 года №190-Ф3. В нем содержатся основные понятия, требования к порядку разработки и содержанию документов, полномочия органов местной и региональной власти. Кроме этого, правовой основой служат Земельный кодекс Российской Федерации, Жилищный кодекс Российской Федерации, федеральные законы и иные нормативно-правовые акты Российской Федерации, а также законы и нормативно-правовые акты субъектов Российской Федерации. Законы и принимаемые в соответствии с ними иные нормативные правовые акты Российской Федерации и субъектов Российской Федерации, содержащие нормы, регулирующие отношения в области градостроительной деятельности, не могут противоречить Градостроительному кодексу Российской Федерации.

Законодательство о градостроительной деятельности является предметом совместного ведения Российской Федерации и субъектов Российской Федерации. Это означает, что нормативно-правовые акты, принимаемые публичными субъектами системы градорегулирования нижних уровней власти, не могут противоречить законодательным и нормативно-правовым актам высших уровней, а изменения Федерального законодательства неизбежно требуют приведения в соответс-



Рис. 1. Принципы правового законодательства о градостроительной деятельности 
твие с федеральным законодательством всех нормативно-правовых актов субъектов Российской Федерации и органов местного самоуправления.

Законодательство о градостроительной деятельности регулирует отношения по территориальному планированию, градостроительному зонированию, планировке территории, архитектурно-строительному проектированию, возведению и реконструкции объектов капитального строительства, а также капитальному ремонту в том случае, если он затрагивает конструктивные и иные параметры, характеризующие безопасность и надежность подобных объектов. В связи с этим правовое законодательство и изданные в соответствии с ним нормативно-правовые акты должны основываться на определенных принципах, представленных на рисунке 1.

Правовое регулирование вопросов градостроительной деятельности на муниципальном уровне. Как уже говорилось выше, органы местного самоуправления в рамках своих компетенций вправе принимать местные нормативно-правовые акты, регламентирующие градостроительную деятельность. Подобными нормативными правовыми актами признаются постановления глав муници- палитетов, районов, городов, сел и поселков, специальных территорий, закрытых территориальных образований [12]. Все они устанавливают обязательные правила для населения самоуправляемых территорий, учреждений и организаций, осуществляющих свою деятельность в пределах этих территорий, и так или иначе отражают то разнообразие методов, способов, форм, в которых организовано и продолжает развиваться местное самоуправление в России [13]. Полномочия органов местного самоуправления представлены на рисунке 2.

В статье 18 Градостроительного кодекса Российской Федерации представлен перечень документов территориального планирования муниципального образования. Данный перечь документов представлен на рисунке 3 .

Состав, порядок подготовки документов территориального планирования муниципальных образований, порядок подготовки изменений и внесения их в такие документы, а также состав, порядок подготовки планов реализации таких документов устанавливаются в соответствии с Градостроительным кодексом Российской Федерации и иными нормативными правовыми актами субъектов Российской Федерации, нормативными правовыми актами органов местного самоуправления.

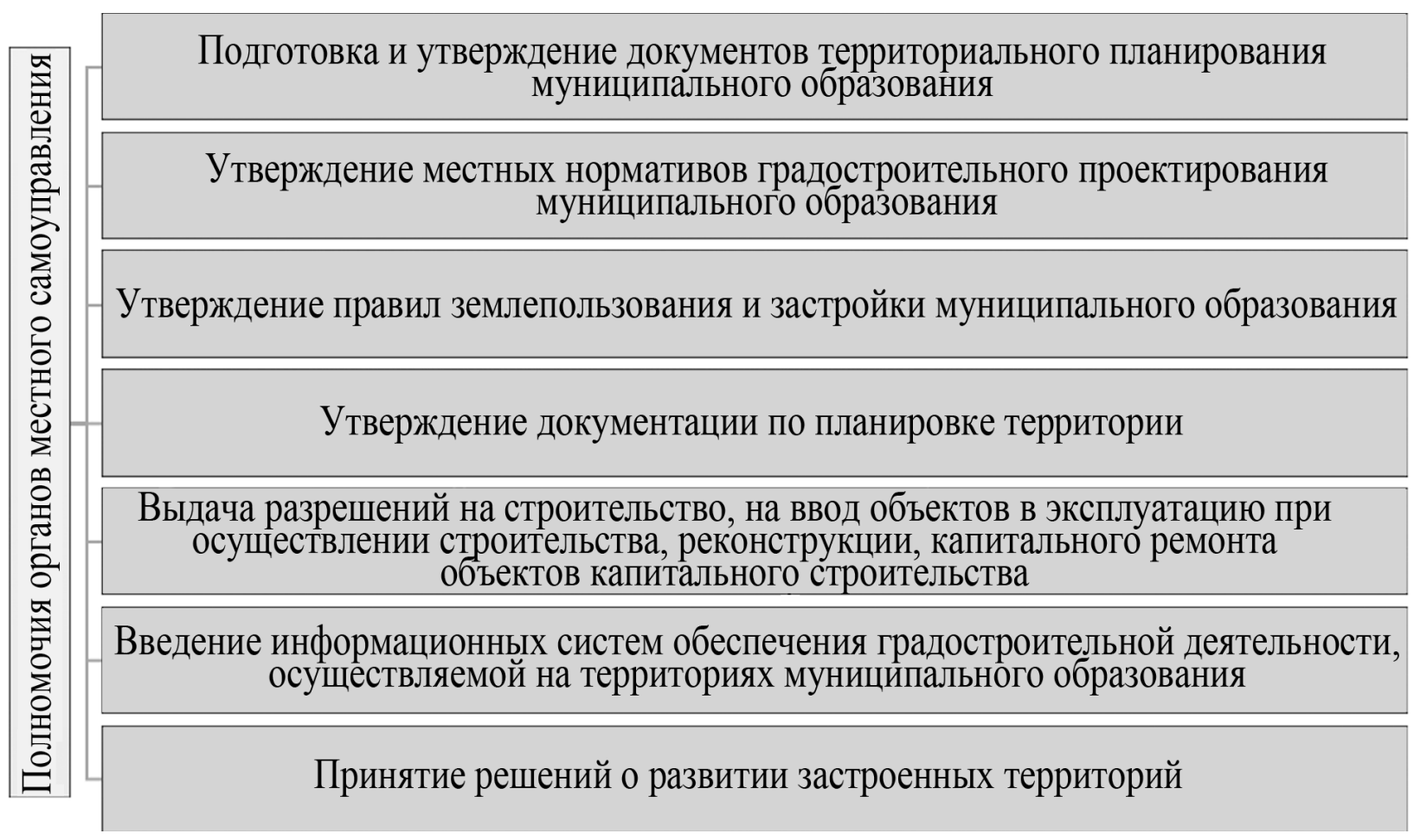

Рис. 2. Полномочия органов местного самоуправления 
Схема территориального планирования муниципального образования является особым видом документации территориального планирования, которым должны располагать администрации муниципальных образований. На основании такого документа решаются вопросы, касающиеся земельноимущественных отношений, а также дается разрешение на строительство и реконструкцию объектов капитального строительства. С одной стороны, схема территориального планирования является необходимым этапом документального оформления процесса хозяйственного развития территории, а с другой стороны, служит инструментом для определения возможных направлений развития территории.

Помимо схемы, согласно Градостроительному кодексу Российской Федерации одним из основных документов территориального планирования является и Генеральный план. Планировка, застройка, реконструкция и иные виды градостроительной деятельности выполняются на основании такого проектного документа. Важным элементом генерального плана является масштабное изображение, получаемое путем графического наложения чертежа проектируемого объекта на топографический, фотографический или инженерно-топографический план территории. Объектами проектирования могут быть как земельные участки со всеми архитектурными сооружениями, так и целые города или муниципальные районы [14].

Структура правовой основы управления в области градостроительной деятельности имеет определенные особенности, свойственные только ей. Правила землепользования и застройки и градостроительные регламенты, в частности, подготовленные и утвержденные органами местного самоуправления поселений, муниципальных образований и городских районов, обязательны для исполнения не только физическими и юридическими лицами, но и представителями других органов публичной власти, других субъектов регулирования - Российской Федерацией, субъектов Российской Федерации.

При этом полномочия в управлении градостроительной деятельностью и градорегулирования разных уровней публичной власти - Российской Федерации, субъектов Российской Федерации, органов местного самоуправления - не пересекаются между собой. Это означает, что не существует очередности в подготовке документов территориального планирования. В случае неимения документов территориального планирования Российской Федерации или ее субъектов органы местного самоуправления на землях, отнесенных к их ведению, могут осуществлять территориальное планирование в пределах своих компетенций. Именно такой подход и обеспечивает упорядоченный уровень в организации территории. При этом важным остается условие согласования проектов документов территориального планирования другими органами публичной власти, а также учет документов территориального планирования и документации по планировке территории при подготовке проектов градостроительного проектирования.

Можно сказать, что отсутствие подобных пересечений в полномочиях субъектов публичной власти создает необходимость использования совместных технологий в области подготовки документов территориального планирования [12, 15].

Отличительной чертой градостроительного регулирования является то, что население и владельцы недвижимости выступают равноправными субъектами регулирования

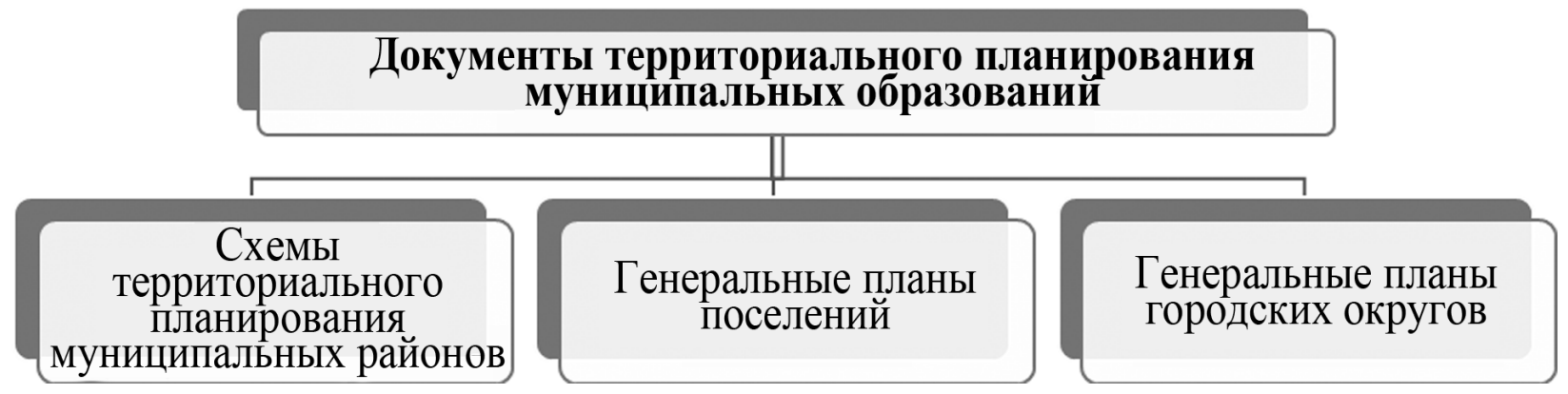

Рис. 3. Документы территориального планирования муниципальных образований 
градостроительной деятельности. В связи с этим обязательным условием является проведение публичных слушаний, на которых рассматриваются различные вопросы правил землепользования и застройки.

Заключение. Как видим, градостроительное проектирование - это не мода или современный стиль общества, а вполне закономерный процесс, который включен в градостроительную систему, результатом которой является законченный строительный объект, соответствующий установленным нормативно-правовым актам, правилам и нормам, действующим на определенной территории.

\section{Литература}

1. Овчинникова Н.Г. Совершенствование управления градостроительным комплексом на территории Ростовской области. Интеграционные процессы в современном геоэкономическом пространстве. Материалы научно-практической конференции. - 2016. - С. 234-236.

2. Овчинникова Н.Г. Социо-эколого-экономическоемоделированиепроцессов управления земельными ресурсами в сфере сельскохозяйственного производства / Terra Economicus. 2011. - T. 9. - №3-2. - C. 89-91.

3. Овчинникова Н.Г. Разработка и принятие проектных решений по организации рационального использования земельных ресурсов. Известия Ростовского государственного строительного университета. 2011. - №15. - C. 225-230.

4. Овчинникова Н.Г., Гончарова С.Н. Оценка производственного потенциала сельскохозяйственных предприятий. Интернет-журнал «Науковедение». - 2012. - №3 (12). - С. 112.

5. Овчинникова Н.Г., Шумкова Е. С. Учетно-регистрационный процесс в системе управления земельными ресурсами. Экономика и экология территориальных образований. 2016. - №2. - C. 125-129.

6. Русских А.В., Овчинникова Н.Г. Значимость документов территориального планирования муниципального образования для ведения ЕГРН. Электронный сетевой политематический журнал «Научные труды КубГТУ». - 2017. — №4. - C. 285-289.

7. Овчинникова Н.Г., Шмакова В.В. Организация рационального использования земельных ресурсов при территориальном планировании муниципальных образований. Экономика и экология территориальных образований. - 2017. - №4. - С. 80-90.

8. Овчинникова Н.Г., Алиева Н.В. Территориальные условия организации использования земельных ресурсов / Инженерный вестник Дона. - 2012. - №3 (21). C. $836-839$.

9. Овчинникова Н.Г. Использование и охрана земельных ресурсов в системе рационального землепользования / Землеустройство, кадастр и мониторинг земель. - 2011.№6 (78). - С. 83-91.

10. Овчинникова Н.Г. Организационнотерриториальные аспекты использования земельных ресурсов / Инженерный вестник Дона. - 2011. - Т. 17. - №3. - С. 236-240.

11. Овчинникова Н.Г. Территориальноградостроительное развитие Ростовской области в современных условиях / Строительство и архитектура - 2015. Материалы международной научно-практической конференции ФГБОУ ВПО «Ростовский государственный строительный университет», Союз строителей Южного федерального округа, Ассоциация строителей Дона. - 2015. C. 243-244.

12. Чешев А.С., Овчинникова Н.Г. Концептуальные основы формирования механизма устойчивого землепользования / Terra economicus. - 2008. - T. 6. - №2-2. C. $115-118$.

13. Чешев А.С., Овчинникова Н.Г. Экологические аспекты формирования землепользования в новых условиях хозяйствования / Terra economicus. - 2008. - T. 6. №3-3. - C. 68-70.

14. Овчинникова Н.Г., Чешев А.С. Организационно-правовые формы хозяйствования в современных условиях / Инженерный вестник Дона. - 2011. - Т. 15. - №1. C. $279-288$.

15. Новик Ю.С., Овчинникова Н.Г., Зерщзиков A.M. Основные направления градостроительного развития южного региона России / Организационно-экономические проблемы регионального развития в современных условиях. Материалы международной научно-практической конференции. - 2017. C. $227-229$. 


\section{References}

1. Ovchinnikova N.G. Sovershenstvovan ie upravlenija gradostroitel'nym kompleksom na territorii Rostovskoj oblasti. Integracionnye processy v sovremennom geojekonomicheskom prostranstve. Materialy nauchno-prakticheskoj konferencii [Improving the management of urban development in the Rostov region. Integration processes in the modern geoeconomic space. Materials of the scientific and practical conference]. - 2016. - Pp. 234-236.

2. Ovchinnikova N. G. Socio-jekologojekonomicheskoe modelirovanie processov upravlenija zemel'nymi resursami $\mathrm{v}$ sfere sel'skohozjajstvennogo proizvodstva [Socioecological and economic modeling of land management processes in the field of agricultural production] / Terra Economicus. - 2011. Vol. 9. — №3-2. — Pp. 89-91.

3. Ovchinnikova N. G. Razrabotka i prinjatie proektnyh reshenij po organizacii racional'nogo ispol'zovanija zemel'nyh resursov. Izvestija Rostovskogo gosudarstvennogo stroitel'nogo universiteta [Development and adoption of design decisions on the organization of rational use of land resources. Proceedings of the Rostov state University of civil engineering]. — 2011. №15. - Pp. 225-230.

4. Ovchinnikova N.G., Goncharova S.N. Ocenka proizvodstvennogo potenciala sel'skohozjajstvennyh predprijatij [Assessment of the production potential of agricultural enterprises]. Internet-zhurnal «Naukovedenie». — 2012. №3 (12). - Pp. 112.

5. Ovchinnikova N. G., Shumkova E.S. Uchetno-registracionnyj process $\mathrm{v}$ sisteme upravlenija zemel'nymi resursami. Jekonomika i jekologija territorial'nyh obrazovanij [Accounting and registration process in the land management system. Economics and ecology of territorial formations]. - 2016. - №2. - Pp. 125-129.

6. Russkih A. V., Ovchinnikova N.G. Znachimost' dokumentov territorial'nogo planirovanija municipal'nogo obrazovanija dlja vedenija EGRN. Jelektronnyj setevoj politematicheskij zhurnal «Nauchnye trudy KubGTU» [Significance of territorial planning documents of a municipality for maintaining the unified state register of Russian regions. Electronic network polythematic journal «Scientific works of KubSTU»]. — 2017. №4. - Pp. 285-289.
7. Ovchinnikova N. G., Shmakova V.V. Organizacija racional'nogo ispol'zovanija zemel'nyh resursov pri territorial'nom planirovanii municipal'nyh obrazovanij. Jekonomika i jekologija territorial'nyh obrazovanij [Organization of rational use of land resources in territorial planning of municipalities. Economics and ecology of territorial formations]. — 2017. №4. - Pp. 80-90.

8. Ovchinnikova N. G., Alieva N. V. Territorial'nye uslovija organizacii ispol'zovanija zemel'nyh resursov [Territorial organization of land use] / Inzhenernyj vestnik Dona [Engineering journal of Don]. - 2012. — №3 (21). - Pp. 836-839.

9. Ovchinnikova N. G. Ispol'zovanie i ohrana zemel'nyh resursov $\mathrm{v}$ sisteme racional'nogo zemlepol'zovanija [Use and protection of land resources in the system of rational land use] / Zemleustrojstvo, kadastr i monitoring zemel' [Land management, cadastre and monitoring of lands]. — 2011. — №6 (78). — Pp. 83-91.

10. Ovchinnikova N. G. Organizacionnoterritorial'nye aspekty ispol'zovanija zemel'nyh resursov [Organizational-territorial aspects of land use]/Inzhenernyj vestnik Dona [Engineering journal of Don]. — 2011. — Vol. 17. — №3. Pp. 236-240.

11. Ovchinnikova N.G. Territorial'no-gradostroitel'noe razvitie Rostovskoj oblasti V sovremennyh uslovijah [Territorial and urban development of the Rostov region in modern conditions] / Stroitel'stvo i arhitektura 2015. Materialy mezhdunarodnoj nauchnoprakticheskoj konferencii FGBOU VPO «Rostovskij gosudarstvennyj stroitel'nyj universitet», Sojuz stroitelej Juzhnogo federal'nogo okruga, Associacija stroitelej Dona [Construction and architecture-2015. Materials of international scientific-practical conference of FSBEI HPE «Rostov State Construction University», Union of builders of the Southern Federal district, Association of builders of Don]. - 2015. - Pp. 243-244.

12. Cheshev A.S., Ovchinnikova N. G. Kon ceptual'nye osnovy formirovanija mehanizma ustojchivogo zemlepol'zovanija [Conceptual bases of formation of mechanism of sustainable land management] / Terra economicus. 2008. - Vol. 6. - №2-2. - Pp. 115-118.

13. Cheshev A.S., Ovchinnikova N. G. Jekologicheskie aspekty formirovanija zemlepol'zovanija $\mathrm{v}$ novyh uslovijah hozjajstvovanija 
[Environmental aspects of land use in new conditions of managing] / Terra economicus. 2008. - Vol. 6. — №3-3. - Pp. 68-70.

14. Ovchinnikova N.G., Cheshev A.S. Organizacionno-pravovye formy hozjajstvovanija $\mathrm{V}$ sovremennyh uslovijah [Organizational-legal forms of managing in modern conditions] / Inzhenernyj vestnik Dona [Engineering journal of Don]. — 2011. — Vol. 15. — №1. - Pp. 279-288.

15. Novik Ju. S., Ovchinnikova N.G., Zershikov A. M. Osnovnye napravlenija grado- stroitel'nogo razvitija juzhnogo regiona Rossii [Main directions of urban development of the southern region of Russia] / Organizacionnojekonomicheskie problemy regional'nogo razvitija $\mathrm{v}$ sovremennyh uslovijah. Materialy mezhdunarodnoj nauchno-prakticheskoj konferencii [Organizational and economic problems of regional development in modern conditions. Proceedings of the international scientific and practical conference]. - 2017. - Pp. 227-229.

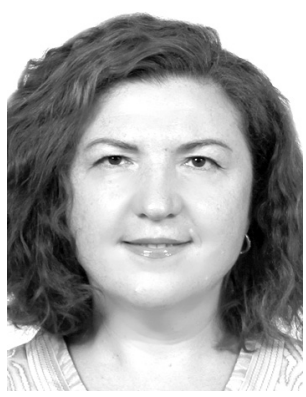

Овчинникова Наталья Геннадьевна - кандидат экономических наук, доцент Донского государственного технического университета.

Ovchinnikova Natalya Gennadyevna - Candidate of Economic Sciences, Associate Professor, Don State Technical University.

344022, г. Ростов-на-Дону, пл. Гагарина, 1

1 Gagarin sq., 344022, Rostov-on-Don, Russia

E-mail: natali281280@yandex.ru 


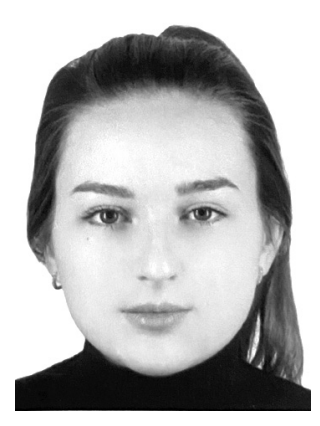

Жидкова Екатерина Ивановна - магистрант кафедры экономики природопользования и кадастра Донского государственного технического университета.

Zhidkova Ekaterina Ivanovna - Master's Student of the Department of Environmental Economics and Cadastre, Don State Technical University.

344022, г. Ростов-на-Дону, пл. Гагарина, 1

1 Gagarin sq., 344022, Rostov-on-Don, Russia

E-mail: natali281280@yandex.ru

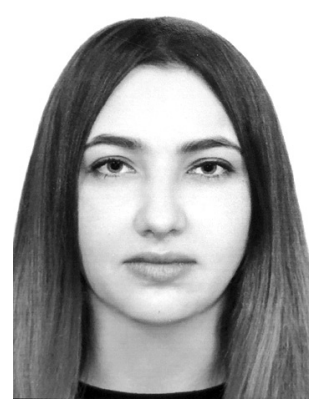

Тимофеева Виктория Анатольевна - магистрант кафедры экономики природопользования и кадастра Донского государственного технического университета.

Timofeeva Victoria Anatolievna - Master's Student of the Department of Environmental Economics and Cadastre, Don State Technical University.

344022, г. Ростов-на-Дону, пл. Гагарина, 1

1 Gagarin sq., 344022, Rostov-on-Don, Russia

E-mail: natali281280@yandex.ru 